\title{
Políticas públicas para museus: o suporte legal no ordenamento jurídico brasileiro
}

Átila Bezerra Tolentino*

\section{Resumo}

O artigo apresenta, de uma forma descritiva, a partir dos textos legais já promulgados e de projetos de leis em tramitação no Congresso Nacional, uma trajetória em prol da implementação de uma política museológica, com ênfase nas realizações do governo federal nos últimos anos. Primeiramente, a abordagem terá como base o texto constitucional, demonstrando, em linhas gerais, quais são as diretrizes do Estado voltadas para a implementação das políticas públicas de cultura e seus reflexos no ordenamento jurídico. Em um segundo momento, será efetuada uma reflexão sobre a Política Nacional de Museus, em atuação desde o ano de 2003. O texto abordará os caminhos legais que se seguiram a partir dela, como uma resposta do Estado à sociedade na implementação de políticas voltadas para o setor museológico brasileiro.

Palavras-chave: Política nacional de museus. Políticas públicas. Legislação cultural.

\section{Public policies to museums: the legal support in brazilian laws}

\begin{abstract}
This article describes the ways undertaken by the federal government in Brazil to implement a public policy to museums, especially from the already promulgated legal texts and from projects of laws in appreciation by the National Congress. First, the approach will have as base the constitutional text, demonstrating, in general lines, which are the lines of direction of the State turned to the implementation of the public policies of culture and its consequences in the legal system. In a second moment, a reflection on the National Policy of Museums will be effected, in performance since the year of 2003. The text will approach the legal ways that had followed from it, as a reply of the State to the society in the implementation of policies directed toward the brazilian museums.
\end{abstract}


Keywords: National policy of museums. Public policies. Cultural rights.

\section{Introdução}

Como bem observa Massa-Azarbe (2007, p.2), a análise das políticas públicas perpassa as disciplinas da Administração Pública e da Ciência Política. Abordar o tema sob a perspectiva do Direito também é tarefa fundamental para os gestores públicos, tendo em vista que as políticas públicas carregam elementos além dos aspectos econômicos e sociais, tendo reflexos no ordenamento jurídico, sobretudo quando tratamos do direito administrativo.

Abordar a atuação do governo nas políticas públicas sob o aspecto jurídico também se justifica pelo fato de, como dito por Maria Paula Dallari Bucci (2007, p.3), que a necessidade de compreensão das políticas públicas como categoria jurídica se apresenta na medida em que se buscam formas de concretização dos direitos humanos, em particular os direitos sociais, direitos esses tratados nas Constituições a partir do século 20, que ultrapassaram os limites da estruturação do poder e das liberdades públicas, e passaram a tratar dos direitos fundamentais em sentido amplo.

Nessa perspectiva, este trabalho buscar apresentar, de uma forma descritiva, a partir dos textos legais já promulgados e de projetos de leis em tramitação no Congresso Nacional, uma trajetória em prol da implementação de uma política museológica, com ênfase nas realizações do governo federal nos últimos anos. Primeiramente, a abordagem terá como base inicial o texto constitucional, apresentando, em linhas gerais, quais são as diretrizes do Estado voltadas para a implementação das políticas públicas de cultura e seus reflexos no ordenamento jurídico.

Posteriormente, será efetuada uma reflexão sobre uma política pública específica, ou seja, a Política Nacional de Museus, em atuação desde o ano de 2003, e quais os caminhos legais se seguiram a partir dela, como uma resposta do Estado à 
sociedade na implementação de políticas voltadas para o setor museológico brasileiro.

\section{As políticas públicas de cultura e seu contexto no ordenamento jurídico}

A base legal das políticas públicas de cultura atuais advém dos artigos 215 e 216 da Constituição Federal. De acordo com o texto constitucional, o Estado garantirá a todos o pleno exercício dos direitos culturais e o acesso às fontes da cultura nacional, e apoiará e incentivará a valorização e a difusão das manifestações culturais, devendo proteger as manifestações das culturas populares, indígenas e afro-brasileiras, e de outros grupos participantes do processo civilizatório nacional.

A Constituição Federal também define o conteúdo do patrimônio cultural brasileiro como os bens de natureza material e imaterial, tomados individualmente ou em conjunto, portadores de referência à identidade, à ação, à memória dos diferentes grupos formadores da sociedade brasileira. E prevê, ainda, que o poder público, com a colaboração da comunidade, promoverá e protegerá o patrimônio cultural brasileiro, por meio de inventários, registros, vigilância, tombamento e desapropriação, e de outras formas de acautelamento e preservação.

Recentemente, por meio da Emenda Constitucional $n^{\circ} 48$, de 10 de agosto de 2005, que acrescenta o $\S 3^{\circ}$ ao artigo 215 , foi instituída a obrigatoriedade de implantação do Plano Nacional de Cultura, de duração plurianual, visando ao desenvolvimento cultural do país e à integração das ações do Poder Público que conduzam à defesa e valorização do patrimônio cultural brasileiro; produção, promoção e difusão de bens culturais; formação de pessoal qualificado para a gestão da cultura em suas múltiplas dimensões; democratização do acesso aos bens de cultura; e valorização da diversidade étnica e regional.

No campo infra-constitucional, anteriormente à Constituição Federal de 1988 CF/88, uma primeira experiência de delimitação de políticas voltadas para o setor cultural pode ser encontrada na Lei $n^{0} 7.505$, de 2 de julho de 1986, conhecida como Lei Sarney. Essa lei dispunha sobre benefícios fiscais na área do imposto de renda concedidos a operações de caráter cultural ou artístico e definia, por meio de suas 
disposições, procedimentos para doação, patrocínio e investimento na área cultural e seus campos de abrangência.

Após a CF/88, foi editada a Lei $n^{\circ}$ 8.313, de 23 de dezembro de 1991, conhecida como Lei Rouanet (1). Essa Lei restabelece os princípios da Lei $n^{\circ} 7.505 / 86$ e cria o Programa Nacional de Apoio à Cultura - Pronac. As finalidades e objetivos do Pronac, previstos em lei, são inspirados no texto constitucional e, para cumpri-los, o Programa prevê dois mecanismos básicos de apoio a projetos culturais: O Fundo Nacional de Cultura - FNC e o Incentivo a Projetos Culturais - Mecenato (2).

O FNC é um fundo proveniente de arrecadação e outros recursos públicos para investimento direto em projetos culturais, mediante celebração de convênios e outros instrumentos similares. O Mecenato, por sua vez, viabiliza benefícios fiscais para investidores que apóiam projetos culturais sob forma de doação ou patrocínio. Empresas e pessoas físicas podem utilizar a isenção em até $100 \%$ do valor no imposto de renda devido e investir em projetos culturais. Além da isenção fiscal, elas investem também em sua imagem institucional e em sua marca.

Segundo José Álvaro Moisés, a diferença fundamental entre as duas leis

“[...] está em que, enquanto a Lei Sarney apenas exigia que os produtores culturais e as empresas que quisessem investir em cultura se cadastrassem no Ministério [da Cultura] - e a negociação do apoio aos projetos culturais era feita diretamente no mercado -, a Lei Rouanet considera que o dinheiro que o empresário investe em cultura é imposto que ele vai deixar de recolher aos cofres públicos e, por isso, os projetos devem ser previamente apresentados por seus proponentes - artistas, produtores culturais, instituições ou mesmo empresas -, para análise do Ministério da Cultura." (MOISÉS, 1997, p.18).

A Lei Rouanet, entretanto, não chegou a resolver o problema de tirar das mãos do mercado a condução das políticas para o setor cultural. Primeiramente, porque os recursos oriundos do FNC são bastante escassos para atender a uma demanda mínima para a implementação das políticas públicas de cultura no país, sobrecarregando o mecanismo do Mecenato. Em segundo lugar, embora a Mecenato permita que os projetos culturais sejam apoiados por meio de renúncia fiscal, tratando-se, portanto, de recursos públicos, as empresas não o concebem 
dessa forma. Além dos benefícios fiscais, esse mecanismo promove um alto retorno publicitário às empresas quando se apóia um projeto de grande visibilidade. Desta forma, as empresas acabam apoiando apenas projetos que dêem retorno de imagem, como museus de grande porte, artistas conhecidos e megaeventos, restringindo-se basicamente ao eixo Rio-São Paulo. Ou seja, embora o Ministério da Cultura selecione quais projetos culturais podem receber patrocínio, é o mercado que determina quais projetos serão apoiados.

Em estudo sobre o marketing cultural, Ana Carla Fonseca Reis ressalta que a

"[...] delegação de parte da produção cultural do país ao setor privado não significa transferência do delineamento da política cultural. Ao contrário, exige que a política pública esteja claramente definida, para que possa surtir efeito mesmo envolvendo grande participação privada. O setor privado constitui de fato uma excelente fonte de recursos ao financiamento da cultura, mas somente se os incentivos à sua participação estiveram concatenados com os da política cultural pública." (REIS, 2003, p.150).

Se não houver políticas públicas definidas, devidamente normatizadas e que orientem os investidores culturais, a prática de deixar ao mercado a seleção dos projetos culturais a serem apoiados causa distorções no setor cultural brasileiro. Os artistas e as instituições culturais que mais necessitam de apoio do Estado, e as regiões menos privilegiadas, são amplamente prejudicados por esse mecanismo. Em função dessas distorções, o Ministério da Cultura manifestou a necessidade de o próprio governo federal propor um projeto para alteração da Lei Rouanet, com a finalidade de apresentar um novo modelo de cultura no país (3). A alteração na lei não chegou a ser efetuada, mas foi editado o Decreto $n^{\circ} 5.761$, de 27 de abril de 2006, que regulamenta a Lei 8.313/91 e estabelece sistemática de execução do Pronac. O decreto buscou corrigir práticas que contribuem para as falhas da lei, prevendo, inclusive, que a execução do Pronac deve obedecer às normas, diretrizes e metas estabelecidas em seu plano anual, que deve estar de acordo com o plano plurianual do governo e com a Lei de Diretrizes Orçamentárias. O plano anual do Pronac deve ser elaborado pelo Ministério da Cultura até 30 de novembro do ano anterior. 
Para que o Pronac e seu plano anual tenham sucesso em seus resultados, é necessário que a ele sejam atreladas políticas públicas consistentes, com objetivos e metas definidos. A ausência dessas políticas públicas contribuiu para que se adotasse, no Ministério da Cultura, a política de "atendimento de balcão". Isto é, as ações adotadas foram pontuais, sem um planejamento sistemático. Criou-se uma política de "departamento de marketing" em detrimento de uma política cultural. 0 Pronac tornou-se um mero repassador de recursos a proponentes de projetos apresentados ao Ministério da Cultura, quando cabia a ele conduzir políticas públicas de cultura, gerenciar e acompanhar a aplicação dos recursos transferidos e avaliar os resultados obtidos.

A mudança dessa postura pôde ser percebida na área museológica quando da criação de uma política pública em nível nacional, a Política Nacional de Museus, após amplo debate com o setor no ano de 2003. Essa política propiciou a aplicação regular dos recursos previstos no Pronac, como também a constituição de uma rede de parcerias que congregasse a utilização de financiamentos por meio das leis de incentivo fiscal e orçamentos próprios dos órgãos e das entidades envolvidos, valorizando a integração entre os entes da federação e da sociedade civil organizada voltada para o campo museológico.

\section{A Política Nacional de Museus}

Segundo Maria Paula Dallari Bucci, os instrumentos orçamentários dispostos na Constituição Federal, plano plurianual (PPA), lei de diretrizes orçamentárias (LDO) e lei orçamentária podem ser considerados as expressões jurídicas de políticas públicas, por excelência. Essa vocação é da própria natureza do instrumento e já vinha afirmada no art. $2^{\circ}$ da Lei $n^{\circ} 4.320$, de 17 de março de 1964 , que se refere à "política econômico-financeira" e a "programa de trabalho do Governo", que vem a ser, aliás, a razão de ser da lei orçamentária (BUCCI, 2007, p. 17).

Criado pela CF/88, o plano plurianual - PPA (4) configura-se um novo instrumento gerencial adotado pelo governo federal, que tem como finalidade articular planejamento e orçamento e deve ser integrado à lei de diretrizes orçamentárias e à lei orçamentária anual. O escopo temporal do PPA é de quatro anos, tendo início no 
segundo ano de cada governo e terminando no primeiro ano do governo subseqüente.

No segundo governo do Presidente Fernando Henrique Cardoso, o PPA 2000-2003 foi elaborado a partir do estudo dos Eixos Nacionais de Integração e Desenvolvimento. Esse PPA, intitulado "Avança Brasil”, adotou o sistema de gestão por programas, ou seja, a partir dos estudos realizados foram formulados programas específicos que tinham o objetivo de responder às demandas da sociedade em diversos segmentos: saúde, educação, moradia, segurança, cultura, transporte, saneamento básico e etc. Essa atuação do governo federal demonstra o que observa Maria das Graças Rua, ao salientar que

“[...] grande parte da atividade política dos governos destina-se à satisfação das demandas dos atores sociais ou das reivindicações formuladas pelos próprios agentes do sistema político, ao mesmo tempo que articulam os apoios necessários." (RUA, 2002, p.234).

Um dos programas criados nesse PPA foi o programa Museu, Memória e Cidadania (5), que tem como objetivo revitalizar os museus e criar condições para a sua autosustentabilidade. Esse programa foi então a resposta dada pelo governo federal à demanda do setor museológico brasileiro em termos de política pública para essa área.

No entanto, o programa Museu, Memória e Cidadania, em sua versão inicial, estava longe de um ideal para responder adequadamente a uma demanda da sociedade em termos de políticas públicas voltadas para o setor museológico. Primeiramente, o programa foi concebido para atender especificamente aos museus da União, quando cabe ao governo federal a implementação de políticas públicas direcionadas ao setor museológico como um todo. Tal fato também prejudica o caráter de integração entre os entes da federação. Um dos pressupostos do PPA é a promoção de parcerias entre governo federal, estados, municípios e sociedade civil organizada para viabilizar a execução dos seus programas. Ao se restringir aos museus federais, o Programa inibia a construção de uma rede de parcerias entre os entes da federação, necessária para a promoção e a valorização do patrimônio cultural musealizado. 
A definição de uma política pública em nível nacional para o setor museológico era essencial para que se propiciasse a regular aplicação dos recursos previstos no PPA e dos oriundos de incentivo fiscal.

Pensando nisso, no mês de maio de 2003, o Ministério da Cultura, após amplo debate com a comunidade museológica, lançou as bases da política do governo federal para o setor, com a apresentação do caderno "Bases para a Política Nacional de Museus - Memória e Cidadania" (6). O documento apresenta, como objetivo da Política, o seguinte:

\footnotetext{
"Promover a valorização, a preservação e a fruição do patrimônio cultural brasileiro, considerado como um dos dispositivos de inclusão social e cidadania, por meio do desenvolvimento e da revitalização das instituições museológicas existentes e pelo fomento à criação de novos processos de produção e institucionalização de memórias constitutivas da diversidade sócio, étnico e cultural do país." (BRASIL, 2003, p.8).
}

Para tanto, a Política Nacional de Museus apresenta sete eixos programáticos: 1) gestão e configuração do campo museológico; 2) democratização e acesso aos bens culturais; 3) formação e capacitação de recursos humanos; 4) informatização de museus; 5) modernização de infra-estruturas museológicas; 6) financiamento e fomento para museus; 7 ) aquisição e gerenciamento de acervos museológicos. Os eixos são compostos de metas específicas, previstas para serem implementadas em quatro anos.

A Política Nacional de Museus representou uma mudança de postura do Ministério da Cultura, tendo em vista que abrange todos os museus brasileiros, independentemente da sua vinculação institucional, ou se público ou privado. Em todo o seu texto, está premente a articulação entre os entes da federação e da sociedade civil, bem como há a preocupação com a consolidação de políticas públicas não só voltadas aos bens culturais nacionais, mas também aos estaduais e municipais. 
O primeiro reflexo dessa Política foi a mudança do escopo do Programa Museu, Memória e Cidadania, reformulado no PPA 2004-2007. Anteriormente voltado apenas para os museus federais - e na prática somente aos museus vinculados ao próprio Ministério da Cultura -, o Programa passou a abranger todos os museus, de modo a ter consonância com a Política Nacional de Museus. Além disso, as ações do programa também foram reformuladas, a fim de ter coerência com os eixos programáticos da Política.

As ações que se deslancharam após a Política Nacional de Museus também contribuíram para o cumprimento de uma das suas metas, ou seja, a criação do Sistema Brasileiro de Museus - SBM. Em nível nacional, a institucionalização de um sistema de museus veio atender a uma antiga demanda do setor museológico explicitada no documento base da PNM, pois uma das premissas dessa Política é a constituição de uma ampla e diversificada rede de parceiros que, somando esforços, contribuam para a valorização, a preservação e o gerenciamento do patrimônio cultural brasileiro, de modo a torná-lo cada vez mais representativo da diversidade étnica e cultural do país.

O SBM foi instituído por meio do Decreto $n^{\circ} 5.264$, de 5 de novembro de 2004, em meio a um período de grande efervescência no setor museológico brasileiro, em que a sociedade civil teve a oportunidade de debater suas propostas e finalidades.

Cabe destacar que os países onde existem sistemas ou redes de museus demonstram que essa experiência tem contribuído extremamente para o desenvolvimento e fomento dos museus da região. No Brasil, a experiência também tem demonstrado a eficácia dos sistemas estaduais de museus para o desenvolvimento das instituições. Estados que se anteciparam na criação de sistemas de museus, tenham sido eles oficializados ou não, detêm uma política para a área mais consolidada e conseguiram sistematizar as informações sobre os seus museus (7).

De acordo com o texto do Decreto, o SBM fica vinculado ao Ministério da Cultura MinC, a quem cabe a coordenação do Sistema. O SBM tem a finalidade de promover a interação entre os museus brasileiros; o registro e disseminação dos 
conhecimentos do campo museológico; a gestão integrada e o desenvolvimento das instituições, acervos e processos museológicos; e o desenvolvimento de ações de capacitação, documentação, pesquisa, conservação e difusão entre as unidades museológicas que integram o Sistema.

Quanto à estrutura, o Decreto prevê que integram o SBM as instituições museológicas vinculadas ao MinC e, poderão fazer parte, mediante formalização de instrumento hábil, as demais instituições museológicas, museus comunitários, ecomuseus, escolas e universidades que mantenham cursos relativos ao campo museológico, e outras entidades organizadas vinculadas ao setor museológico.

Com o intuito de garantir a representatividade do setor museológico no Sistema e a democratização da condução das políticas públicas para a área, o SBM dispõe de um Comitê Gestor, que tem a finalidade de propor diretrizes e ações, bem como apoiar e acompanhar o desenvolvimento do campo museológico brasileiro.

Na composição do Comitê Gestor, está garantida a representação dos seguintes órgãos ou entidades: Ministério da Cultura, Instituto do Patrimônio Histórico e Artístico Nacional, Ministério da Educação, Ministério da Defesa, Ministério da Ciência e Tecnologia, Ministério do Turismo, sistemas estaduais de museus, sistemas municipais de museus, museus privados, Conselho Federal de Museologia, ecomuseus e museus comunitários, Comitê Brasileiro do Conselho Internacional de Museus, Associação Brasileira de Museologia e instituições universitárias que tenham cursos relacionados à área de museologia. Como se observa, o Comitê Gestor não é composto somente de instituições públicas. Com o SBM, a sociedade civil organizada ligada à área museológica adquiriu a oficialização necessária junto ao Estado para poder participar da condução das políticas públicas para o meio museológico.

Também é atribuição do SBM propor a criação e o aperfeiçoamento dos instrumentos legais para o melhor desenvolvimento das instituições museológicas no Brasil. Dentre as mais diversas e significativas necessidades do setor museal, distingue-se a falta de regulamentação, a disparidade de procedimentos e a ausência de critérios na gestão e nas práticas do setor museológico. Com fins de 
regulamentar a área, o Comitê Gestor do SBM entregou à Câmara Federal, em 2006, o anteprojeto de lei do Estatuto dos Museus. A Comissão de Educação e Cultura apresentou o anteprojeto ao Plenário da Casa, transformando-o no Projeto de Lei $n^{\circ} 7.568 / 2006$.

Antes de se chegar ao Congresso Nacional, a primeira formatação da proposta para o Estatuto foi seguida de profícuas discussões no campo museológico brasileiro, envolvendo pessoas e entidades vinculadas à museologia, meio universitário, profissionais da área e secretarias estaduais e municipais de cultura, ambientadas em diversos fóruns e por meio virtual. Coube ao Comitê Gestor do SBM sistematizar as sugestões e contribuições recebidas, consolidando a proposta de Estatuto dos Museus.

O Estatuto, além de definir o conceito de museu, estabelece os procedimentos de criação de instituições museológicas, identifica suas funções e atribuições, e regula outras atividades específicas. Inclui, ainda, dispositivos que regulamentam uma aplicação uniforme entre os regimes de proteção ao patrimônio cultural, sem os quais não é possível tornar efetivas as mudanças propostas.

Um dos pontos mais relevantes desenvolvido no Estatuto encontra-se no dever dos museus de elaborar e implementar um plano museológico, contendo diagnóstico participativo, identificação dos espaços e conjuntos patrimoniais sob a guarda dos museus, identificação dos públicos destinatários e dos programas essenciais. Os planos museológicos devem caracterizar-se também pela exeqüibilidade, adequação às especificações dos distintos programas do museu, apresentação de cronograma de execução, explicitação da metodologia adotada, descrição das ações planejadas e implantação de um sistema de avaliação permanente.

O Projeto de Lei $n^{\circ} 7.568 / 2006$, se aprovado, será um marco jurídico que busca dar condições para o desenvolvimento dos museus e o fortalecimento das redes e sistemas de museus existentes. Trata-se, portanto, de uma significativa regulamentação que visa a promover o pleno exercício dos direitos culturais e o acesso às fontes da cultura nacional, na medida em que se apóia e incentiva a valorização do patrimônio cultural brasileiro sob a guarda dos museus. 


\section{Considerações finais}

Em seu capítulo sobre a cultura, o texto constitucional reflete grande preocupação com a preservação e a promoção do patrimônio cultural brasileiro. O artigo 216 é basicamente dedicado ao tema. Nesse aspecto, os museus têm o papel relevante de desempenhar, dentro das políticas culturais, a preservação e a difusão do patrimônio cultural de uma determinada nação, assim como o desenvolvimento cultural, científico e educativo dos países e de seus povos.

Uma política pública em nível nacional voltada para o setor museológico, fincada no ideal de democracia, na gestão compartilhada do patrimônio cultural e no reconhecimento da diversidade étnica e cultural brasileira, é fundamental para se cumprir um direito respaldado constitucionalmente de que o Estado garantirá a todos o pleno exercício dos direitos culturais e o acesso às fontes da cultura nacional (art. 215 , caput da $C F / 88$ ), bem como para a definição das diretrizes para o Plano Nacional de Cultura a ser criado (art. 215, $\S 3^{\circ}$, da CF/88).

Essa política, inserida em um plano maior de uma política cultural para o país, deve também levar em conta a concepção atual de museu, que o considera como uma instituição dinâmica a serviço da sociedade e de seu desenvolvimento, voltada para a pesquisa, educação, deleite e preservação e promoção dos testemunhos do homem e de seu ambiente, ou seja, associada à memória, ao conhecimento e ao prazer.

Isso é o que demonstram Mário Chagas e Nascimento Jr. ao tratarem sobre museus e política:

\footnotetext{
"Na segunda metade do século XX, ou, de modo mais preciso, depois dos anos setenta, a museologia e os museus no Brasil passaram por um grande processo de transformação e amadurecimento. Nesse período, o objeto de estudo da museologia foi construído, desconstruído e reconstruído inúmeras vezes; a categoria museu foi ressignificada e a diversidade tipológica dos museus foi ampliada de uma maneira sem precedentes. Os museus passaram a ser tratados como processos e práticas culturais de relevância nacional. [...]
} 
Essas considerações são relevantes quando se trata de pensar e colocar em prática uma política pública específica para museus. Em outras palavras: a construção, na contemporaneidade, de uma política museal democrática e de interesse público precisa considerar a museodiversidade brasileira, bem como as reflexões, os debates, as práticas e as poéticas características desse universo em expansão." (NASCIMENTO JÚNIOR; CHAGAS, 2006, p.14).

O envolvimento da sociedade civil na implantação da Política Nacional de Museus e no desenvolvimento das ações do SBM é fundamental para que se contribua para a perenidade das políticas públicas de cultura voltadas para o setor museológico. É o que tem acontecido com o Sistema de Museus do Rio Grande do Sul, que vem perdurando além de vários governos (8).

A participação dos setores não governamentais no SBM corrobora o que Silva e Melo afirmam em sua análise sobre o processo de implementação de políticas públicas no Brasil:

\footnotetext{
"O conceito de redes de implementação é particularmente apropriado para capturar o fato de que as políticas públicas são implementadas fundamentalmente através de redes de agentes públicos e, cada vez mais freqüentemente, também por agentes não governamentais. [...] Ao se reconhecer o jogo político como essencial à vida democrática e fundamental para o controle social da ação do governo, contribuições recentes têm enfatizado a importância de se incorporar stakeholders - grupos envolvidos pelas políticas e nela interessados - ao processo de formulação e implementação de políticas." (SILVA; MELO, 2000, p.12).
}

A esse fator, acrescente-se a institucionalização de ordenamentos jurídicos que regulamentem a atuação do Estado na área, fundamentais para o comprometimento dos governos na continuidade das políticas públicas.

\section{Notas}

(1) Após a CF/88, alguns estados, em cumprimento ao $\S 6^{\circ}$ do seu art. 216 , também editaram leis estaduais instituindo incentivos fiscais para fomento à cultura, como a Lei $n^{\circ} 7.015$, de 9/12/1996, do estado da Bahia, que instituiu o programa Faz Cultura. 
(2) Além dos dois citados, a Lei Rouanet também prevê o Fundo de Investimento Cultural e Artístico - Ficart, que, no entanto, nunca foi aplicado na prática.

(3) Entre os meses de junho a agosto de 2003, o Ministério da Cultura promoveu o conjunto de seminários "Cultura para Todos", com o objetivo de discutir e propor um novo modelo de financiamento da cultura. Os seminários aconteceram em 15 cidades brasileiras e envolveram artistas, produtores culturais, servidores do próprio Ministério e secretários de cultura de todo o país.

(4) O texto constitucional trata do PPA em seus artigos 165 e 166.

(5) O Programa Museu, Memória e Cidadania era chamado na época de Museu, Memória e Futuro. O programa é composto de recursos orçamentários oriundos do Tesouro Nacional e do Fundo Nacional de Cultura.

(6) A primeira apresentação pública do texto sobre as bases para a Política Nacional de Museus foi no mês de março de 2003, quando foram realizados fóruns de discussões junto à comunidade museológica. Posteriormente, o texto foi disseminado por meio eletrônico para que pudessem ser apresentadas sugestões.

(7) No plano internacional, podemos citar como exemplo o Sistema Espanhol de Museus, criado pelo Decreto Real $n^{\circ}$ 620, de 10/08/87; o Sistema de Museus da Catalunha, criado pela Lei $n^{\circ} 17$, de 2/11/90, e regulamentado pelo Decreto $n^{\circ} 35$, de 10/02/92; e a Rede Portuguesa de Museus, criada pelo Decreto-Lei $n^{\circ}$ 398 , de 13/10/99, e regulamentada pela Lei $n^{\circ} 47$, de 19/08/04. No Brasil, o principal exemplo de sistema de museus consolidado é o Sistema Estadual de Museus do Rio Grande do Sul, criado pelo Decreto $n^{\circ} 33.791$, de 21/01/91. Também cabe ressaltar que a institucionalização do SBM impulsionou a criação de outros sistemas, como é o caso do Sistema de Museus do Estado do Ceará, instituído pela Lei no 13.602, de 28/06/05, o Sistema de Museus da cidade de Pelotas, criado pelo Decreto $n^{\circ} 4.895$, de 15/09/06, e o Sistema de Museus de Ouro Preto, criado pela Lei $n^{\circ} 305$, de 20 de dezembro de 2006.

(8) Estudo detalhado sobre o SEM/RS, de autoria da professora Thais Gomes Fraga, pode ser encontrado na edição n.1 da Revista Brasileira de Museus e Museologia - Revista Musas.

\section{Referências Bibliográficas}

BRASIL. Ministério da Cultura. Bases para a Política Nacional de Museus: Memória e Cidadania. Brasília: Minc, 2003

Política Nacional de Museus: Relatório de Gestão 2003-2006. Brasília: Minc / Iphan / Demu, 2006.

BUCCI, Maria Paula Dallari (Org.). Políticas públicas e Direito. São Paulo: Saraiva, 2007. No prelo.

ESPANHA. Ministerio de Educación y Cultura. Normativa sobre el patrimonio histórico cultural. Madrid: Dirección General de Cooperación y Comunicación Cultural, 1998. Colección Análisis y Documentos. Tomos I y II 
FRAGA, Thais Gomes. Sistema Estadual de Museus do Rio Grande do Sul: a incessante construção de uma política museológica. Musas - Revista Brasileira de Museus e Museologia, Rio de Janeiro: Iphan, v.1, p.107-120, 2004.

MASSA-ARZABE, Patrícia. Dimensão jurídica das políticas públicas. In: BUCCl, Maria Paula Dallari (Org). Políticas públicas e Direito. São Paulo: Saraiva, 2007. p.1-26. No prelo.

MOISÉS, José Álvaro. Democracia e financiamento da cultura no Brasil. In: MOISÉS, José Álvaro; BOTELHO, Isaura (Org). Modelos de financiamento da cultura. Os casos do Brasil, França, Inglaterra, Estados Unidos e Portugal. Rio de Janeiro: Funarte, 1997. p.13-22.

NASCIMENTO JR., José do; CHAGAS, Mário; Museus e política: apontamentos de uma cartografia. In: Caderno de diretrizes museológicas. Brasília: Iphan, 2006. p.13-17.

PEÑUELA, Lluís (Ed.). Manual jurídico de los museos. Cuestiones prácticas. Madrid: Diputación de Barcelona, 1998.

REIS, Ana Carla Fonseca. Marketing cultural e financiamento da cultura: teoria e prática em um estudo internacional e comparado. São Paulo: Pioneira Thomsom Learning, 2003.

RUA, Maria das Graças. Análise de políticas públicas: conceitos básicos. s.i, s.d. mimeografado. Disponível em: <http://www.ufba.br/\%7Epaulopen/ADM_Instituicoes_e_Politicas_Publicas.html> Acesso em: 10 dez. 2006.

SILVA, Pedro Luiz Barros; MELO, Marcus André Barreto de. O processo de implementação de políticas públicas no Brasil: características e determinantes de programa e projetos. Campinas: Unicamp/Nepp, 2000. (Caderno n. 48)

* Graduado em Letras Português pela Universidade de Brasília. Especialista em políticas públicas e gestão governamental pela Escola Nacional de Administração Pública. Gerente de Gestão Museológica no Departamento de Museus e Centros Culturais do Instituto do Patrimônio Histórico e Artístico Nacional do Ministério da Cultura. 